\title{
Tien Shan Geohazards Database: Landslide susceptibility analysis
}

\author{
H.B. Havenith ${ }^{\text {a,* }}$, A. Torgoev ${ }^{\text {a }}$, R. Schlögel ${ }^{\text {b }}$, A. Braun ${ }^{\text {c }}$, I. Torgoev ${ }^{\text {d }}$, A. Ischuk $^{e}$ \\ a Department of Geology, University of Liege, Liege, Belgium \\ b Institut du Physique du Globe de Strasbourg, CNRS UMR 7516, Univ. de Strasbourg/EOST, Strasbourg Cedex, France \\ c Department of Engineering Geology and Hydrogeology, RWTH Aachen University, Aachen, Germany \\ ${ }^{\mathrm{d}}$ Institute of Geomechanics and Development of Subsoil, Academy of Sciences, Bishkek, Kyrgyzstan \\ e Institute of Geology, Earthquake Engineering and Seismology, Academy of Sciences, Dushanbe, Tajikistan
}

\section{A R T I C L E I N F O}

\section{Article history:}

Received 27 August 2014

Received in revised form 20 January 2015

Accepted 17 March 2015

Available online $\mathrm{xxxx}$

\section{Keywords:}

Landslide susceptibility

Morphology

Lithology

Seismo-tectonic factors

Landslide inventory verification

Central Asia

\begin{abstract}
A B S T R A C T
This paper is the second part of a new geohazards analysis applied to a large part of the Tien Shan, Central Asia, focused on landslide susceptibility computations that are based on recently compiled geographic, geological and geomorphological data. The core data are a digital elevation model, an updated earthquake catalogue, an active fault map as well as a new landslide inventory. The most recently added digital data are a new simplified geological map, an annual precipitation map, as well as river and road network maps that were produced for the Kyrgyz and Tajik parts of the Tien Shan. On the basis of these records we determine landslide densities with respect to morphological $(M)$, geological $(G)$, river distance $(R)$, precipitation $(P)$, earthquake $(E)$ and fault $(F)$ distance factors. Correlations were also established between scarp locations and the slope angle, distance to rivers, curvature. These correlations show that scarps tend to be located on steeper slopes, farther from rivers and on more convex terrain than the entire landslides. On the basis of the landslide density values computed for each class of the aforementioned factors, two landslide susceptibility maps are created according to the Landslide Factor analysis: the first one considers correlations between the landslide occurrences and the first four factors (MGRP); the second one is based on the first map (MGRP) combined with the seismo-tectonic influence $(+\mathrm{E}+\mathrm{F}$ ) on landslide distributions. From the comparison of these two maps with actual landslide distributions we infer that the distances to rivers as well as to faults and past earthquakes most strongly constrain the susceptibility of slopes to landslides. We highlight several zones where the landslide susceptibilities computed for the MGRP + E + F factors fit better the observed concentration of landslides than those computed for the MGRP factors alone. For a few zones, both maps produce high landslide susceptibilities that do not well reflect the observed low sub-regional landslide activity; for some cases, we consider that some influencing factors must not have been well taken into consideration, for others we show that we simply had missed landslide detections.

At the scale of the mountain range, the computed landslide susceptibility maps fit the observed landslide distributions relatively well, but these maps only represent the spatial component of landslide hazards. Temporal aspects are not considered by this analysis.
\end{abstract}

(c) 2015 Elsevier B.V. All rights reserved.

\section{Introduction}

In this paper we present a new landslide susceptibility study applied to a large part of the Tien Shan, Central Asia. The basic inputs are a recently compiled landslide inventory as well as an updated earthquake catalogue and active fault map that have already been introduced in the companion paper by Havenith et al., this issue. This companion paper first provides a definition of the mapped 'landslides', considered as coherent mass movements: rockslides, rock avalanches and deepseated slope failures marked by large displacements, mass movements in soils and soft sediments, but mostly excluding debris flows or

\footnotetext{
* Corresponding author.

E-mail address: HB.Havenith@ulg.ac.be (H.B. Havenith).
}

singular rock falls. Second, it establishes links between the landslide and the seismo-tectonic activity on the basis of size-frequency analyses and presented case histories of earthquakes that triggered landslides in many areas of the target region. Here, this study is extended to statistical spatial correlations that are also applied to other environmental factors potentially influencing the regional susceptibility to slope failure.

The first landslide susceptibility map covering the entire target region including the Kyrgyz and Tajik parts of the Tien Shan was presented by Nadim et al. (2006). That study was part of worldwide assessment of landslide and avalanche occurrence probabilities on the basis of morphological, geological, meteorological and seismological data. As they worked at a very global scale, outputs were presented at a low resolution (kilometric or even lower). For the entire Central Asian Mountain regions, they estimate that global landslide hazard can be rated as medium to very high. They further noted that some 
areas in Tajikistan are marked by the highest mortality risk due to landslides. More detailed sub-regional landslide susceptibility (LS) analyses were presented in the same period by Havenith et al. (2006a, b) for areas in the Central Tien Shan and the Maily-Say Valley, respectively. The evolution of landslide activity in the Maily-Say Valley over the past 50 years has been detected and analysed on the basis of preexisting landslide maps and new analyses of aerial photographs as well as Quickbird images (Schlögel, 2009). Size-frequency analyses applied to the five landslide inventories from 1962 to 2007 show that both the number and size of related mass movements increased. In addition, the decreasing power-law exponent over time may indicate that landslide-related hazards are increasing in the Maily-Say Valley (Schlögel et al., 2011)

Those previous studies used sub-regional inventories with 200 up to 500 mapped landslides, which are also part of the new much larger landslide inventory that represents the basis for the present susceptibility analyses. The general statistical method used for our previous LS mapping was the pixel-based Landslide Factor Analysis. This one as well as other more sophisticated statistical methods (e.g. the Conditional Analysis based on the determination of Unique Condition Units, see Carrara et al., 1995; Clerici et al., 2002) were applied to the LS analysis within the Suusamyr Basin (Havenith et al., 2006a). Additional statistical methods for LS analysis were applied to the Maily-Say Valley in a local study, such as the Information Value method, a bivariate statistical method (Yin and Yan, 1988) as well as various data mining techniques, where a multi-parameter input dataset was examined for patterns related to landslide occurrence (Braun, 2010). Related results were compared with those of a process-based (in its original form) or better analytical technique (the Newmark analysis). This latter method is commonly used to evaluate LS in seismically active regions since it was shown that in some cases such geotechnical models can successfully predict the regional failure potential (Jibson et al., 1998; Miles and Ho, 1999). The analysis by Havenith et al. (2006a) showed that the Newmark method produced LS values fitting particularly well with local landslide densities in the Suusamyr Basin if faults were considered as seismic sources. The main disadvantage of most sophisticated LS mapping methods, especially of the analytical ones is that they require a large number of inputs, including geotechnical data, which are generally not available (at the required resolution) for very large areas, such as an entire mountain range. Therefore, here, only the relatively simple Landslide Factor Analysis is applied as it fits well for a LS analysis applied to a large part of the Tien Shan for which far less detailed information is available than for the smaller sub-regions. The method is based on the calculation of landslide densities within the different classes of various environmental factor maps.

The goal of the present work is not to test the performance of various LS mapping methods such as in our previous study applied to the Suusamyr Basin but to evaluate the respective contribution of different environmental factors to landslide susceptibility at the scale of a mountain range. Here, we define landslide susceptibility as a spatial occurrence probability related to slope failure without considering its size of its activity in time (see, e.g., Aleotti and Chowdhury, 1999). As indicated above, particular focus will be on the influence of seismotectonic factors on the regional landslide susceptibility. The main reasons for this particular focus are the high level of seismic hazard in most regions of the Tien Shan (see Abdrakhmatov et al., 2003; Bindi et al., 2012) and the relatively frequent triggering of large landslides $\left(>10 \times 10^{6} \mathrm{~m}^{3}\right)$ by earthquakes (Havenith and Bourdeau, 2010). During the last century, these earthquake-triggered mass movements also caused the most severe natural disasters inside or near the mountains of the Tien Shan (see e.g. Gubin, 1960; Evans et al., 2009, for the Mw $=7.4,1949$, Khait earthquake or Ishihara et al., 1990, for the $\mathrm{Mw}=5.5,1989$, Gissar earthquake). Some of them were related to consequential effects such as river damming by landslides, dam breach and downstream floods; a review of such effects in the Tien Shan is presented in the companion paper by Havenith et al., this issue.

\section{Tien Shan Geohazards Database - inputs}

For the compilation of nearly continuous datasets, for the landslide susceptibility mapping and for the production of raster information, the following geographic extent was defined (using projection of UTM 43 N, false easting 500,000): W-E - 200,000-1,000,000; S-N $4,250,000-4,850,000$; thus, the target area covers $1200 \times 600 \mathrm{~km}=$ $720 \cdot 10^{3} \mathrm{~km}^{2}$.

The basic layer of the geohazards database is the SRTM $90 \mathrm{~m}$ Digital Elevation Model (DEM) that was re-sampled and interpolated at a resolution of $100 \mathrm{~m}$. All other raster-image data were produced at the same $100 \mathrm{~m}$ resolution.

\subsection{Landslide inventory, earthquake catalogue and digital active fault map}

The earthquake catalogue and the digital active fault map, both produced by the Central Asia Seismic Risk Initiative (CASRI) project (see, e.g., Bindi et al., 2012), cover the entire territory of Central Asia, also the areas outside the target region while a homogeneous landslide map has only been compiled within the aforementioned geographic extent ( $\mathrm{Mw} \geq 6.5$ earthquake epicentres, active fault lines and landslides are shown in Fig. 1). The landslide inventory and earthquake catalogue are presented and analysed in detail (including size-frequency statistics) in the companion paper by Havenith et al., this issue. The active fault map is also used as background information in that paper, but a more detailed analysis of the spatial relationship between the faults and landslides will be presented below. For these faults, maximum possible magnitudes have been estimated as well as the recurrence of such magnitudes; however, here we only consider the location of the faults and not their estimated respective activity.

Landslides were mainly digitized within Google ${ }^{\odot}$ Earth; the digitized outlines were then reformatted as shapefile (polygon entities) for use on a common GIS platform (here, ArcGIS ${ }^{\odot} 10.2$ ). This mapping had been completed only recently since for many areas high-resolution imagery was not available on Google ${ }^{\odot}$ Earth before 2012. The entire landslide inventory includes 3462 mapped landslides: including rockslides, rock avalanches, deep-seated mass movements, loess landslides and landslides in other soft soils and sediments; the outlines cover both the source and deposition (for landslide with large displacements) area; debris flows and rockfalls have only been mapped if associated with large coherent mass movements. In the companion paper by Havenith et al., this issue, the landslide inventory has been subdivided into 1) a rockslide dataset (1389) and 2) a soft rock-earth slide dataset (1807); 3) a small dataset of landslides mapped outside the countries of Kyrgyzstan and Tajikistan for which the geology is not known (240); and 4) a local dataset of 26 landslides, drawn on the basis of an existing map (Gubin, 1960) of mass movements triggered by the Khait earthquake in 1949 (26). However, for the landslide susceptibility analyses presented below, the types of landslides have not been considered (the entire inventory was used for all analyses, see landslides outlined by dark dots and polygons in Fig. 1). The reason for this is that we want to determine the general effect of seismo-tectonic factors on slope stability at the scale of a mountain range disregarding the type of potential failure. Type-specific landslide susceptibility mapping is planned for sub-regions (for which more detailed geological-geotechnical information is available) in the near future. Such an approach will also be based on separated inventories for depositional and source areas. Here, some qualitative indications of landslide type-specific susceptibility will be provided for some sub-regions, notably to outline the particular behaviour of landslides and flows in loess deposits.

For at least 100 landslides in hard and soft rocks, field observations have been collected over more than 15 years. For sub-regions, such as the Maily-Say Valley also high-resolution imagery (panchromatic and multi-spectral Quickbird) had been used to map landslides (see Schlögel et al., 2011). First mapping of landslides (before 2006) was also completed with Corona, Aster and SPOT imagery. 


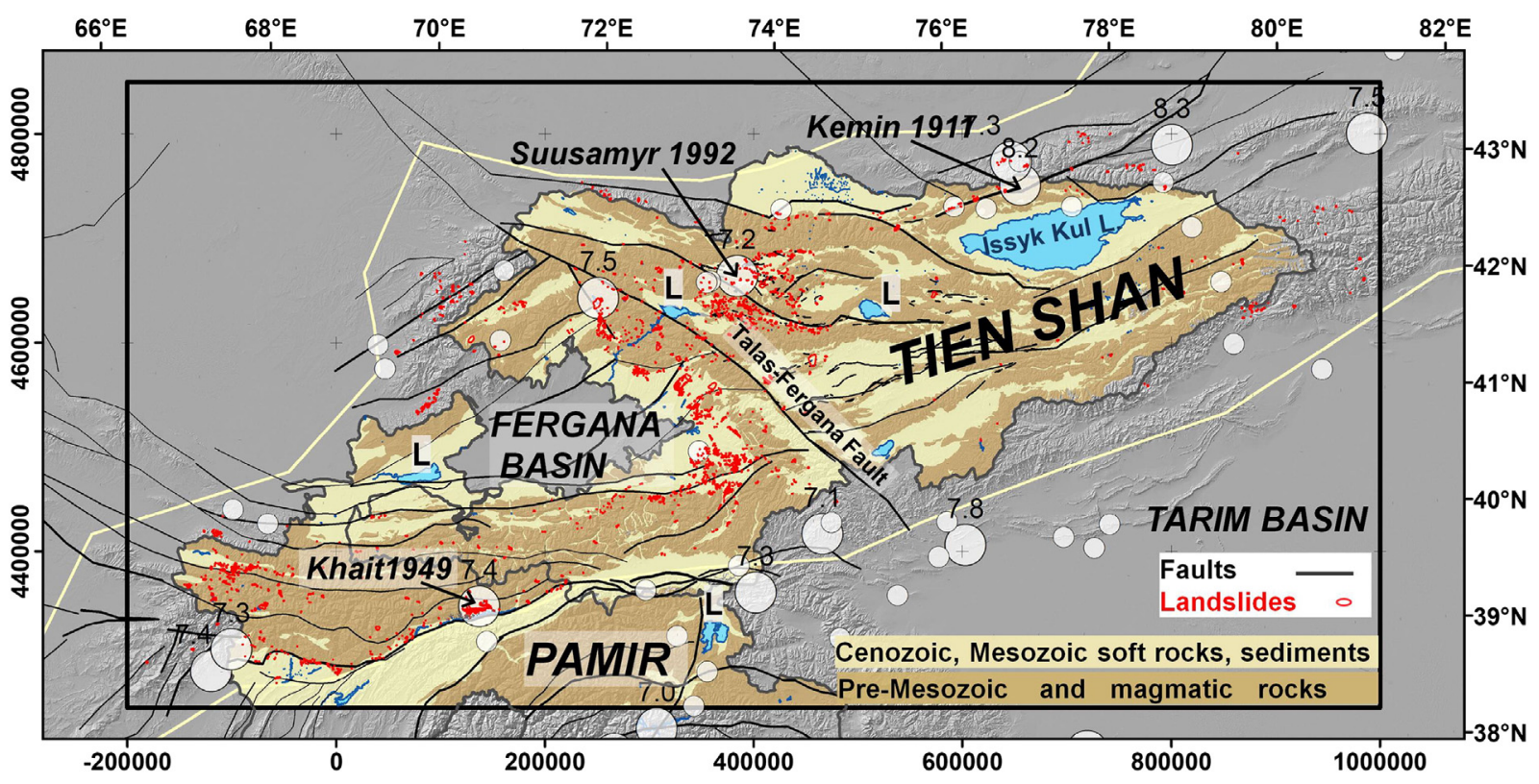

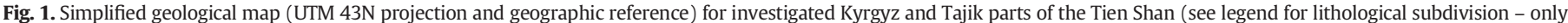

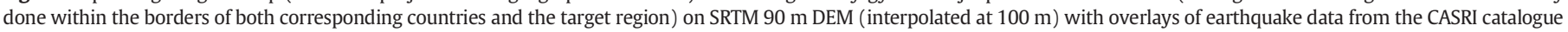

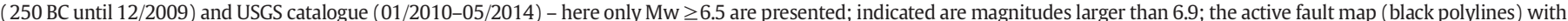

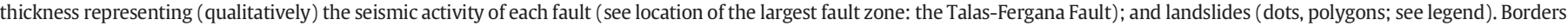


location of major lakes.

\subsection{Geological, geographic, hydrologic and climatic data}

Most of the geological, geographic (road network, location of towns and villages, and others), climatic (average annual precipitation) and hydrologic (digital map of rivers) information was provided by the Ministries of Emergency Situations of Kyrgyzstan (GIS laboratory) and Tajikistan.

For Kyrgyzstan, a fully digitized geological map was provided while for Tajikistan only a scanned geological map was available ('Geological map of the territory of Tajikistan and neighbouring areas, scale $1: 500,000,1984$ '). The latter was georeferenced and only two types of formations were distinguished and digitized: hard rock (pre-Mesozoic and intrusive rocks) and soft rocks and sediments (Mesozoic, Cenozoic). The combined simplified geological map of both countries (see Fig. 1) shows that the Tien Shan is characterised by alternating, roughly EastWest trending mountain ranges and intramontane basins. Palaeozoic rocks and the older basement constitute the core of the ranges (darkcoloured areas in Fig. 1), whereas the basins are filled by Cenozoic and Mesozoic sediments (light-coloured areas in Fig. 1) and are mostly bordered by oppositely vergent thrust faults (Cobbold et al., 1993). The major fault structures considered as seismically active in Late Pleistocene and Holocene times (Bindi et al., 2012) are outlined in black in Fig. 1.

The geohazards database also includes land-cover (grasslands, forests, and other) data that have not yet been implemented for landslide susceptibility analyses because the data were provided at a much lower (kilometric) resolution and we do not have a continuous set for the two countries of Kyrgyzstan and Tajikistan. The principal geographic information used here is the road network that may also reflect population density (a more extensive and dense network is located in populated areas).

For Tajikistan, a digital map of average annual precipitation (1984) was provided by the Institute of Geology, Earthquake Engineering and Seismology of Tajikistan. For Kyrgyzstan, only the corresponding scanned map was available (provided by the Institute of Water problems and Hydropower of the National Academy of Science of the Kyrgyz
Republic). It was georeferenced and digitized and then combined with the existing digital map of Tajikistan. The compiled map of average annual precipitation covering Kyrgyzstan and Northern Tajikistan is presented together with the landslides (dots, polygons), the river network (light-coloured lines) and road network (dark-coloured lines) in Fig. 2. This compiled map shows that both basins at low and some basins at higher altitudes $(>1500 \mathrm{~m})$ surrounded by mountain ranges are marked by an arid climate (with less than $200 \mathrm{~mm}$ of precipitation per year). The mountain ranges are marked by a semi-arid (200$400 \mathrm{~mm}$ ) to humid climate ( $>700 \mathrm{~mm}$ ), with largest amounts of yearly precipitation (>1000 $\mathrm{mm}$ ) affecting high-altitude west- or northward oriented slopes (reaching $1400 \mathrm{~mm} / \mathrm{year}$ ) on the high western slopes of the central Fergana Range (see large blue areas in the centre of the map in Fig. 2). Above $2500 \mathrm{~m}$ altitude most of the precipitation is recorded as snow falls.

\subsection{Correlation with contributing factors}

A series of environmental factors are considered for the landslide susceptibility analysis: the distance to the road network as a geographic factor; the distance to the river network and the average annual precipitation as hydrological and climatic factors, respectively; the simplified geology and the distance to active faults as geological and seismotectonic factors. The four classical morphological factors, altitude, slope angle and aspect as well as curvature, have also been correlated with landslide occurrence; the influence of terrain curvature will be analysed more in detail as it may also be an indicator of the seismic influence on slope stability. Fig. 3 presents the classified altitude map extracted from the $100 \mathrm{~m}$ SRTM digital elevation model (DEM) of the Central Tien Shan together with the hillshade that provides a rough estimate of the local relief and related morphological characteristics (steepness and orientation of slopes; location of crests and valleys influencing the curvature). In this map, digitized landslides are shown by red polygons. The thick dark lines surrounding the higher parts of most of the landslides in this region represent the outer landslide scarp limits (or 'crowns' defined as a $300 \mathrm{~m}$ buffer around the scarp 


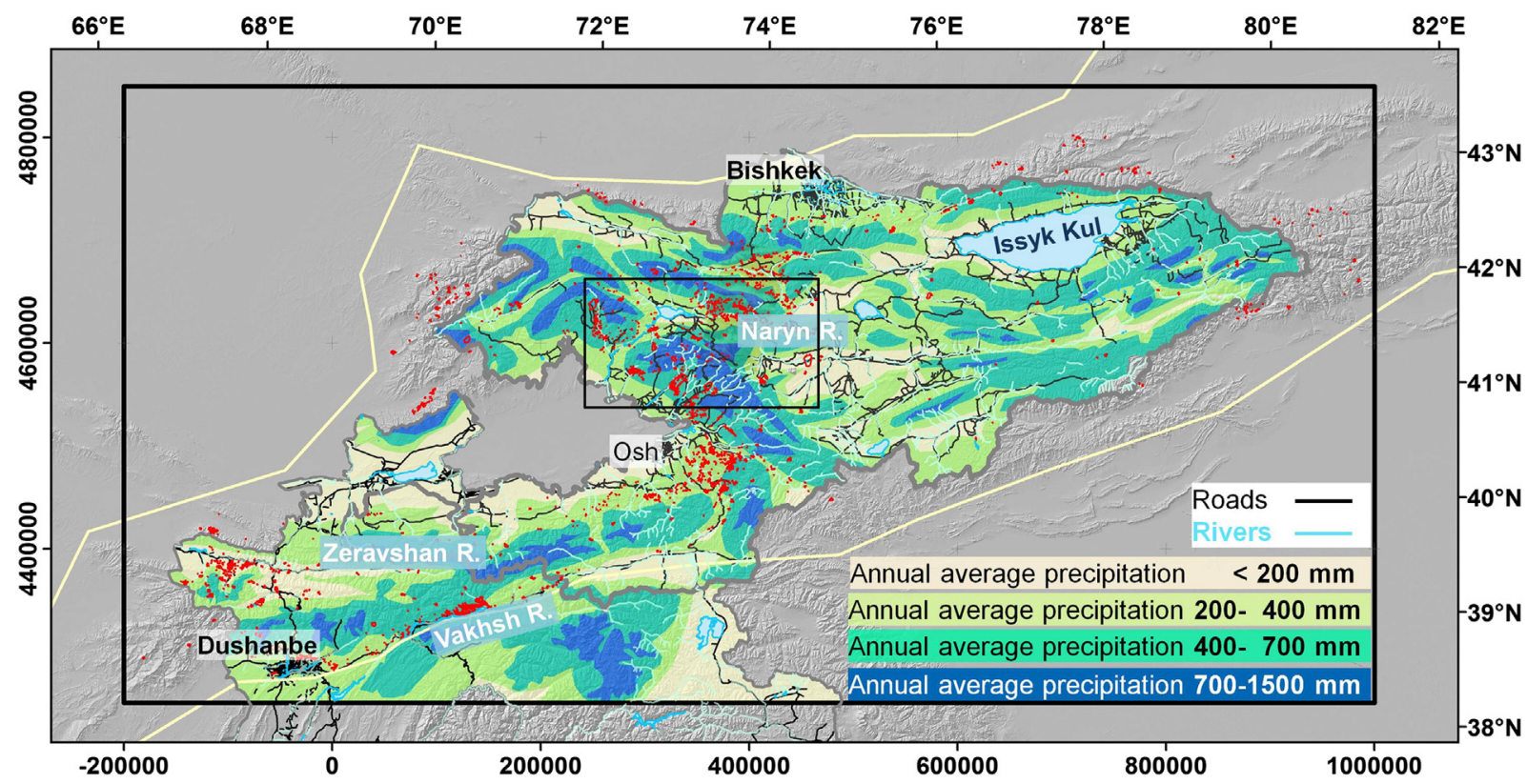

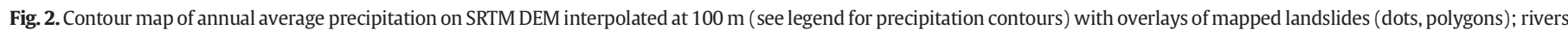
and lakes, road network (line symbols shown in legend). 'L' marks the location of major lakes. The small black rectangle outlines the map shown in Fig. 3.

line). For the entire target region, about 1500 landslide scarps have been outlined (the map in Fig. 3 below shows about 1000 mapped scarps). The mapped scarp buffers were used for correlations with terrain slope and curvature as well as with the distance to rivers.

As we use the Landslide Factor analysis to compute landslide susceptibility, first the landslide densities have to be determined with respect to each class of the different environmental factors. For most factors, a normalised pixel-based density was calculated (Eq. 1), but for the geology also the number of landslides was considered (Eq. 2):

$\mathrm{Ld}_{\mathrm{p}}=\frac{\mathrm{A}_{\mathrm{LPC}}}{\mathrm{A}_{\mathrm{LPT}}} \frac{\mathrm{A}_{\mathrm{PT}}}{\mathrm{A}_{\mathrm{PC}}}$
$\mathrm{Ld}_{\mathrm{n}}=\frac{\mathrm{N}_{\mathrm{LC}}}{\mathrm{N}_{\mathrm{LT}}} \frac{\mathrm{A}_{\mathrm{PT}}}{\mathrm{A}_{\mathrm{PC}}}$

where $\mathrm{Ld}_{\mathrm{p}}$ is the normalised pixel-based landslide density and $\mathrm{Ld}_{\mathrm{n}}$ is the normalised landslide density based on the number of landslides; $A_{\text {LPC }}$ is the area of landslide pixels in each class of the environmental factor map, $A_{L P T}$ is the total area of landslide pixels (of all landslides within the map of factor values), APC is the area of pixels in each class of the environmental factor map, $A_{\mathrm{PT}}$ is the total area of pixels within the environmental factor map; $\mathrm{N}_{\mathrm{LC}}$ is the number of landslides in each class of the environmental factor map, $\mathrm{N}_{\mathrm{LT}}$ is the total number of landslides (within the environmental factor map). $\mathrm{Ld}_{\mathrm{p}}$ and $\mathrm{Ld}_{\mathrm{n}}$ values of 1 indicate

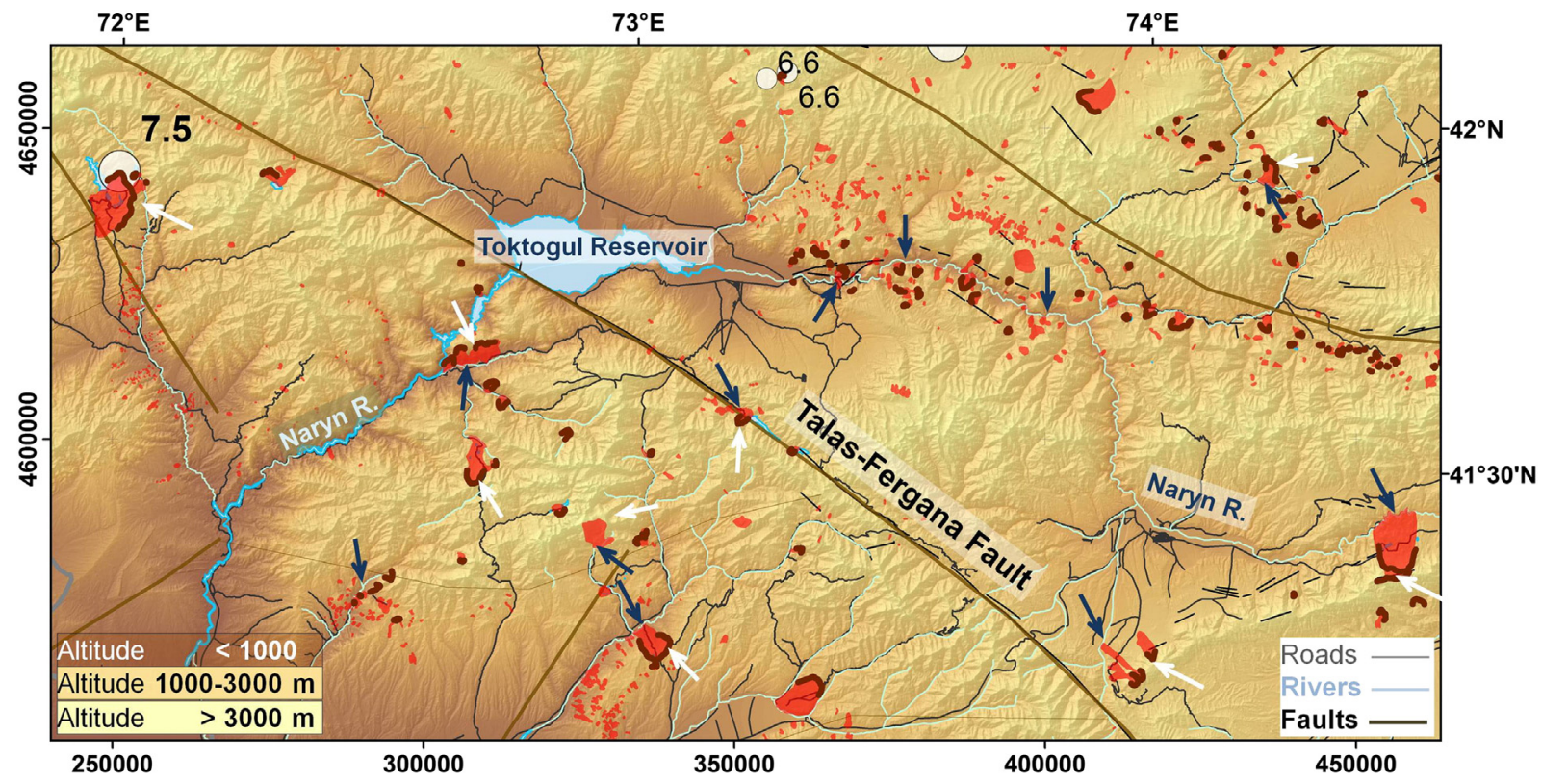

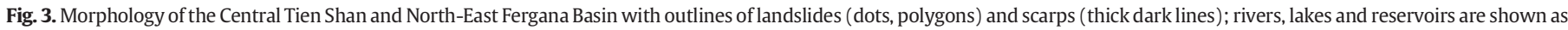

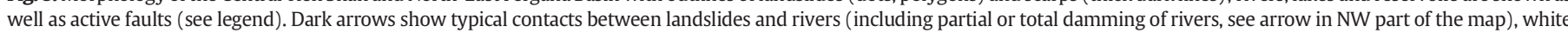
arrows show typical locations of scarps near mountain crests or at crest ends. 
an average landslide density for a factor class; if the same values are less than 1 , a landslide density below average is observed for the respective factor class while values above 1 indicate a landslide density higher than average.

The graph presenting normalised landslide pixel densities with respect to geology (Fig. 4a) shows that more landslide pixels are located in hard rock formations than in soft rock formations (left columns). However, the landslide number density (see middle columns in the same graph) is larger in the soft rocks than in the hard rocks. This difference can be explained by the fact that hard rock landslides are generally (much) bigger than soft rock landslides and flows; thus, even though fewer landslides are located in hard rocks, the density of related pixel areas is higher for the hard rock areas than for the soft rock areas. It should be noticed that in this case the (likely) limited completeness of the landslide inventory for smaller landslides (many areas in the Tien Shan are only covered by 5 or $10 \mathrm{~m}$ resolution SPOT imagery in Google ${ }^{\mathbb{C}}$ Earth) might be one reason for this paradoxically lower landslide density in soft rocks; we consider that most of the 'undetected' smaller $\left(\ll 10^{5} \mathrm{~m}^{3}\right)$ landslides are located in soft rocks (see also discussion on landslide inventory completeness in the companion paper by Havenith et al., this issue). Further, if we exclude zones with slopes smaller than $5^{\circ}$ (generally present in the wide flat areas covered by soft sediments outside the mountain range) from the correlation, we can notice that a slightly higher density of landslide pixels can be observed in soft rock areas than in hard rock areas (green columns). This is due to the fact that the number of pixels in soft rocks is much lower, as almost half of soft-rock pixels are located in zones with slopes smaller than $5^{\circ}$, while less than $10 \%$ of the hard rock pixels are located in these gently dipping or flat areas. Therefore, the ratio of landslide pixel areas per geology class pixels increases for soft rock landslides and comparatively decreases for hard rock landslides. For the landslide susceptibility analysis we considered these latter densities of landslide pixel areas in each geological class (soft rocks have a slightly higher susceptibility to slope instability than hard rocks, respectively marked by values of
1.13 and 0.95$)$. It can be noticed that previous studies by Havenith et al. (2006a,b) showed similarly higher susceptibility of soft rocks to landsliding within two sub-regions of the target area (Suusamyr region and Maily-Say Valley, marked by arrows 'Suu' and 'M-S' in Fig. 4a, respectively). There, it could partly be proved that the lower shear resistance of the materials is responsible for the higher susceptibility to slope failure.

As a climatic factor influencing slope stability we consider the map of average annual precipitation that was compiled from various sources (see above in Fig. 2). The variations in landslide density with respect to the distribution of average annual precipitation (in $\mathrm{mm}$ ) are presented in Fig. 4b. The morphological parameter most strongly influencing precipitation is the altitude. Related correlations (also shown in Fig. 4b) as well as those based on precipitation show that most landslides are located in mid to high altitude zones (1400-2400 m) marked by medium high precipitations (400-700 mm per year). From this graph we can also see that fewer landslides are located at the highest altitudes marked by maximum precipitation - this aspect will be discussed in the next section as it concerns also the validity of the landslide inventory for high mountain areas. The lower concentration of landslides in areas marked by lower precipitation seems to be obvious, but also here indirect effects have to be taken into account: especially zones marked by very low precipitation are located at the bottom of mountain basins or flat lowlands and, for this specific morphological reason, are less susceptible to slope instability. From these observations we infer that the landslide density - precipitation correlation is relatively weak (also due to the likely low resolution of initial rain gauge data used to produce the precipitation map) while the influence of altitude on landslide density is clearly stronger.

The graph in Fig. 4c shows correlations between landslide location and their distance to roads and rivers. It can be seen that most landslides are located near rivers and similarly also close to roads (note the almost overlapping red and blue lines). The fact that landslides (and especially associated deposits) are located close to rivers is almost obvious as
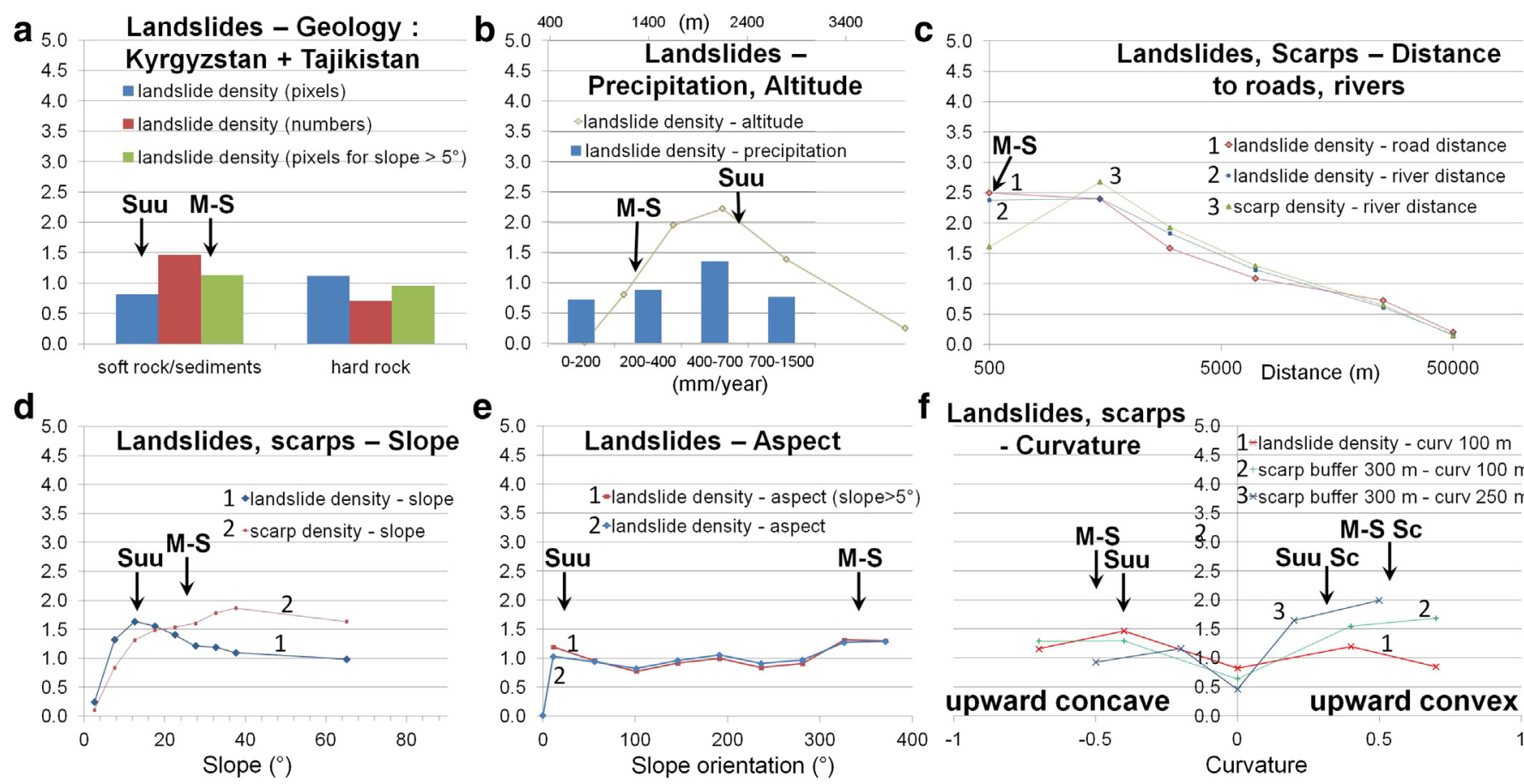

f Landslides, scarps \begin{tabular}{lll} 
- Curvature & 4.5 & 1 *landslide density - curv $100 \mathrm{~m}$ \\
\hline & 2 scarp buffer $300 \mathrm{~m}$ - curv $100 \mathrm{~m}$
\end{tabular}

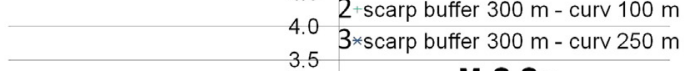

2 landslide density - aspect

$3.5 *$ scarp buffer $300 \mathrm{~m}$ - curv $250 \mathrm{~m}$
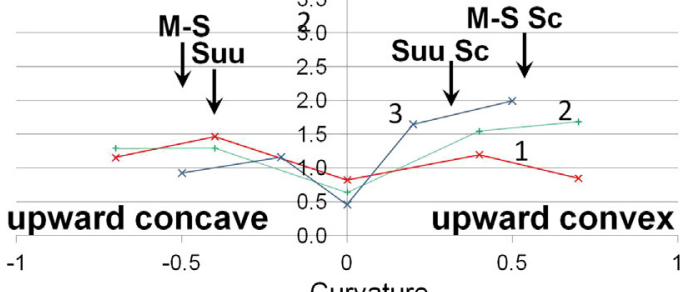

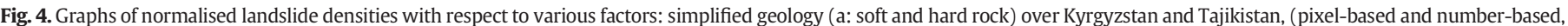

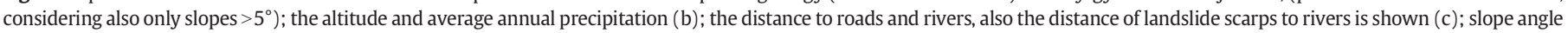

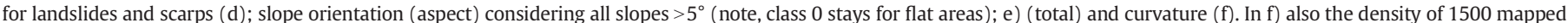

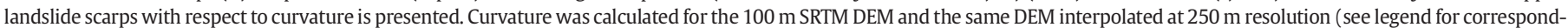

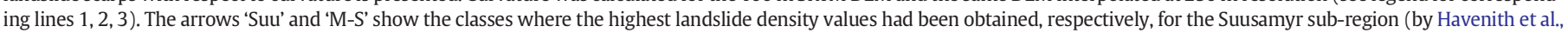
2006a) and for the Maily-Say Valley (by Havenith et al., 2006b). 
landslide material typically moves down to the valley bottom where the rivers are located, but this graph also shows that river erosion must be considered as an important trigger factor. For several large landslides we actually know that they were activated by river erosion. A famous example is the Ayni rockslide that occurred in 1964 along the Zeravshan River (see companion paper by Havenith et al., this issue). However, we also identified source zones (scarps) of many large landslides that were most likely not in contact with any river when the mass movement was activated (see also maximum density of scarp zones at more than $1000 \mathrm{~m}$ away from the river in Fig. 4c (curve 3). Most of these mass movements reached the nearest river due to the large runout (examples are shown in the companion paper by Havenith et al., this issue). The similar proximity of landslides to roads can again be explained by an indirect effect: most roads were built near the rivers along the valley bottoms (where landslide distal zones are often present), because this flat terrain is better for road construction and transport. Actually, we consider that the influence of roads on large slope failures can be considered as very limited while their construction certainly contributes to minor $\left(<10^{5} \mathrm{~m}^{3}\right)$ slope instabilities. In this regard, it should be noted that many large landslides were triggered in pre-historic times when there were no roads.

The correlations between landslide location and the morphological factors, slope angle, slope orientation and curvature are presented in the graphs d), e) and f) in Fig. 4. The two first graphs show that landslides are preferentially located on slopes with an angle of $15-25^{\circ}$ and oriented towards the North-West. The correlation with slope angles is clearly stronger (maximum density of entire landslides of 1.7 for slopes of $15^{\circ}$ ) than the one with slope orientation (maximum density of 1.2 on NW slopes). The high density of landslides in areas marked by relatively gentle slopes $\left(<20^{\circ}\right)$ can be explained by the fact that at least part of the landslide material (now the landslide deposits) had moved to lower more gently sloping areas while the source region is generally marked by larger slope angles (see curve 2 in the graph $4 \mathrm{~d}$ with maximum of scarp density for slopes of about $40^{\circ}$ ). It should be noted that the observation of the weak influence of slope orientation on landslide susceptibility at the scale of the entire Tien Shan shown in Fig. 4e is only partly supported by previous landslide susceptibility studies completed in the aforementioned Suusamyr and Maily-Say regions (Havenith et al., 2006a,b), where densities of landslides (especially in soft rocks and sediments) are clearly higher $(\sim 1.5)$ on NW-N oriented slopes. This locally clear effect of slope orientation on landslide susceptibility is smoother if a large part of the Tien Shan is considered probably due to the different orientations of geological structures (and other changing conditions, such as precipitation distribution) over such large areas.

Finally, we present also spatial correlations between the presence of landslides (and associated deposits) and slope curvature (see curve 1 in the graph $4 \mathrm{f}$ ). The same correlations were also done for scarps of some 1500 large landslides that were mapped (as polylines) all over the Tien Shan (they are shown for a sub-region in Fig. 3). Scarp locations were analysed with respect to curvature for the DEM resampled and interpolated at $100 \mathrm{~m}$ (curve 2 in graph $4 \mathrm{f}$ ) and with respect to a map of curvature computed on the basis of a DEM resampled and interpolated at $250 \mathrm{~m}$ (curve 3 in graph $4 \mathrm{f}$ ). The $250 \mathrm{~m}$ DEM was added to the initial one in order to compute curvature over larger areas and thus to assess the influence of 'lower frequency' topography changes on scarp distributions. The first correlation between landslide (and associated deposits) location and curvature (for $100 \mathrm{~m}$ resolution DEM) shows a slightly larger concentration of mass movement pixels in areas marked by concave surface curvature. However, the landslide scarps are preferentially located on convex slopes. This effect is stronger for the curvature computed from the $250 \mathrm{~m}$ DEM than from the $100 \mathrm{~m}$ DEM. The difference between total landslide density and scarp density over the curvature map can be explained by the fact that large parts of most landslides (belonging to the deposits) moved to areas near the valley bottom (see also correlation with rivers) clearly marked by concave curvature, while the scarps or source areas formed higher on slopes presenting a convex curvature. We already discussed this difference in Havenith et al. (2006a) where we presented a more detailed landslide susceptibility analysis for the Suusamyr Basin. It should be noted that the convex morphology near scarps is partly due to the scarp itself as it represents a local convex slope break (of variable size according to the size of the landslide and the intensity of failure). However, this convex morphology affects only the inner (within the landslide) part of the $300 \mathrm{~m}$ buffer. The other part of the $300 \mathrm{~m}$ buffer is outside the landslide and thus only affected by the natural slope morphology (and not by the specific scarp morphology). The influence of the general convex curvature of larger parts of the mountains on the location of landslide source areas (the scarps), is better highlighted by correlations between scarps and the curvature map computed on the basis of a lower $250 \mathrm{~m}$ resolution DEM. The curvature of each pixel thus represents the morphology of an area with a diameter of at least the double of the pixel size (i.e., $500 \mathrm{~m}$, as the curvature represents the double derivative of the surface). We consider that only a few scarps of very large landslides can induce significant curvature over such an extent; for $90 \%$ of the landslides at least, the curvature computed over this area should represent the one of the natural slope. A more detailed discussion on this particular morphological influence on slope stability is presented below.

\subsection{Comments on particular correlation results}

First, we would like to outline possible reasons for the lower landslide density at higher altitudes marked by larger precipitation rates. On one hand, it could be that not all landslides have been identified at higher altitudes (above $2500 \mathrm{~m}$ ) - especially deep-seated rockslides marked by small displacements or singular rock falls - as not all these areas are covered by high-resolution imagery in Google ${ }^{\mathbb{C}}$ Earth (see also Havenith et al., this issue, for more detail on this aspect); further, we tried to avoid mapping deposits looking similar to moraines (especially where recognition is hampered due to low image resolution). Actually, on older maps from Soviet times many rock avalanche deposits are indicated as moraines as the source area of these mass movements are sometimes located at great distances $(>5 \mathrm{~km})$ from the deposits. On the other hand, the lower landslide susceptibility at higher altitudes can partly be explained by the fact that these areas are often made of stronger rocks, resistant to erosion; further, permafrost contributes to slope stability above altitudes of 3000-3500 m (for most of the Tien Shan). This confirms that no direct link can be established between average annual rainfall distribution and landslide activity if statistics are applied to all the landslides covering the entire territory of the Tien Shan. However, we also know that some specific types of landslides in some sub-regions covered by thick loess deposits, such as earth slides and flows, are preferentially triggered by intense and long lasting rainfall. To outline this dependence of landslide occurrence on precipitation, sub-regional and landslide type-specific correlations would be needed. Such type-specific and sub-regional landslide analysis would also better show the influence of slope orientation on slope stability. For instance, the more 'climatic' Loess flows are clearly distributed within clusters that are not only related to loess cover thickness but also to the wetness of soils that is generally larger on northand north-westward oriented slopes.

Further, the temporal component needs to be considered; e.g., Havenith et al. (2006b) clearly showed that the activation of soft rock landslides in the Maily-Say Valley is strongly influenced by seasonal variations of rainfall and snowmelt. Yet, the effect of rainfall on the stability of large rock slopes cannot be easily shown as these slopes generally respond to long-term climatic changes. For some types of giant rockslides we consider that their triggering is much more controlled by structural and seismo-tectonic factors than by climatic ones (even if we consider different climatic conditions in the past). The structural factor cannot be analysed here as we have only very local information on rock structures, while the tectonic factor can be analysed using the active fault maps (see analysis related to Fig. 6 below). In this regard, 
it is interesting to notice that the source area of the largest rockslide of the Tien Shan, Beshkiol, in Naryn Valley (see red polygon in SE corner of the map in Fig. 3), located in a relatively arid zone is bounded by a series of faults.

Second, it is important to know that some correlations shown above do not only mark landslide susceptibility with respect to a specific environmental factor, but also provide information on the exposure of specific locations or elements to landslide impacts. For instance, the graph in Fig. 4c, highlights the exposure of rivers and roads to landslide impacts. Actually, roads probably belong to the constructed objects that are most frequently impacted by landslides in mountain regions. The exposure of rivers to landslide impacts can even be more important for landslide risk analyses as it is at the origin of new types of induced hazard: the formation of (partial or full) blockages, upstream flooding with possible destabilisation of slopes around the new lake, downstream flooding after (partial or total) dam breach, formation of related debris flows - examples of all these hazards are presented in the companion paper by Havenith et al. (this issue).

Finally, we add one comment concerning the clearly stronger concentration of scarps on convex slopes (especially with respect to curvature computed for a lower resolution $250 \mathrm{~m}$ DEM - compared to the initial interpolated $100 \mathrm{~m} \mathrm{DEM}$ ) while landslide material is preferentially located in concave areas. As already highlighted by Havenith et al. (2003 and Havenith et al., 2006a), this preferential initiation of slope failure near convex morphologies, such as mountain or hill crests, convex slope breaks, borders of canyons and terraces, might be the signature of the seismic influence on slope stability. This signature seems to be particularly strong in the Tien Shan (and even predominant compared to climatic or hydrologic effects if large rock slope failures are considered). Also for other seismic regions and areas hit by known earthquakes, it was shown that landslide scarps are preferentially located near hilltops and convex slope breaks (see, e.g., Harp et al., 1981, for Guatemala and Durville and Méneroud, 1982, for Northern Algeria, among many others). This is due to the fact that the seismic ground motion can be strongly amplified over convex ground surface due to wave focusing effects (induced both by the geometry itself and by the often more strongly weathered rocks forming the convex morphologies). Examples of clear links between landslide occurrence and earthquake ground motion in the Tien Shan are presented in the companion paper by Havenith et al. (this issue).

\subsection{Landslide susceptibility mapping}

On the basis of the previous correlations, a landslide susceptibility map was computed according to the Landslide Factor method. The first step involved the creation of landslide density maps for the different environmental factors: therefore, the landslide density values shown in Fig. 4 were attributed to the corresponding classes of each environmental factor map. Then, various landslide density maps were multiplied with each other to obtain a landslide susceptibility map. For the first landslide susceptibility map 'MGRP' (for morphology, geology, river, precipitation), the landslide density maps computed for slope angle (here the scarp density was used for the part of the inventory where deposits could be separated from source areas to show the respective distribution over slopes) were multiplied with those based on slope orientation, curvature (scarp density for $100 \mathrm{~m}$ DEM curvature was used), altitude, geology (here the density computed for slopes $>5^{\circ}$ was used), distance to rivers and average annual precipitation. The precipitation factor was preferred to the altitude factor as we consider the latter as an indirect trigger (below the permafrost area) while precipitation may directly influence slope stability. The final multiplication product map presented in Fig. 5 shows susceptibility classes corresponding to intervals of multiplied density values. Five susceptibility classes were defined: lowest, low, medium, high and highest. Lowest susceptibility was defined for multiplied density values of less than 0.1 while highest susceptibility was defined for resulting values or more than 10 , smaller intervals were defined for low susceptibilities and bigger ones for large susceptibilities. If we compare the final distribution of landslide susceptibility (LS) values with the actual landslide distribution, we can notice that zones marked by higher landslide concentration are generally also highlighted by increased susceptibility; most of these high to highest susceptibility zones are located along rivers (see greenish areas marking high susceptibility along rivers plotted on the map in Fig. 5). The fit is best where landslides are preferentially located in narrow valleys with steep valley flanks. This can be related to the high density values obtained for the landslide occurrencedistance to rivers correlation (density $>2$ near rivers) that contributes most to the multiplication product. As discussed above, this is not necessarily related to a strong contribution of river erosion to slope instability but is partly depending on indirect factors, such as the steeper slopes located near rivers and the accumulation of landslide material (the deposits) near the valley bottom (even if the initial failure is located relatively far from it). However, we can also outline some problematic zones (see black ellipses in Fig. 5) where the LS either over- or underestimates observed landslide density. For instance, in the Suusamyr Basin (zone 1 in Fig. 5), the computed low LS does not reflect the higher concentration of landslides. The same can be observed for zones 5 and 6 near the south-eastern border of the Fergana Basin while in zones 2, $3,4,7$ and 8 the computations seem to overestimate the actual subregional landslide susceptibility (few landslides were detected in those areas).

Below it will be discussed if the relatively weak concentration of landslides in those 4 areas (and other smaller not highlighted zones) is due to missed landslide detections or due to some additional factors influencing landslide susceptibility that were not considered for this map. The latter could also explain why landslide susceptibility has apparently been underestimated in the zones 1,5 and 6.

Therefore, landslide susceptibility has also been computed by taking into account the seismo-tectonic factors introduced above: the earthquake catalogue and the map of active faults. First, two separate maps of distances, respectively, to $\mathrm{Mw} \geq 6.5$ earthquake epicentres and to faults were computed. For the latter, we considered both, the large active fault map that was produced for all Central Asia (CASRI) and sub-regional fault maps created for the Central Tien Shan. A single distance map was created by computing the square root of the multiplied distances to, respectively, earthquakes and faults.

This resulting map presented in Fig. 6 shows light-coloured zones near past earthquakes and faults and dark-coloured areas far from earthquakes and faults. Landslide densities were calculated with respect to the initial 'distance to $\mathrm{Mw} \geq 6.5$ ', 'distance to fault map' (CASRI fault map), to the 'distance to all faults' (including the CASRI and the subregional Central Tien Shan map). Related correlations are compared to the landslide density-distance to rivers map in the graph shown in lower right corner of Fig. 6 . The correlations between landslide locations and distances to faults/earthquake epicentres all show a higher landslide density near these seismo-tectonic elements. However, compared to the correlation with the landslide density-distance to rivers map, the distribution of landslides is spatially less constrained with respect to the seismo-tectonic elements. This is likely to be related to the wider spatial influence of major fault structures and large earthquakes on slope stability (connected with the dip of faults, most of which are thrust faults with earthquake epicentre locations often far from the fault outcrop, but some large faults also have an important if not predominant strike-slip component as well as the depth of earthquake hypocentres). The same graph in Fig. 6 also shows the landslide densities with respect to the combined distance to earthquake and fault map (curve 4 in the graph in the lower right corner). A series of white arrows plotted on the map in Fig. 6 highlight the presence of landslide clusters near faults or past earthquake epicentres. The most prominent example is the high concentration of landslides in the epicentral area of the $\mathrm{Mw}=7.4$ Khait earthquake that occurred in 1949 in Northern Tajikistan (highlighted in Fig. 6). 
H.B. Havenith et al. / Geomorphology $x x x$ (2015) $x x x-x x x$

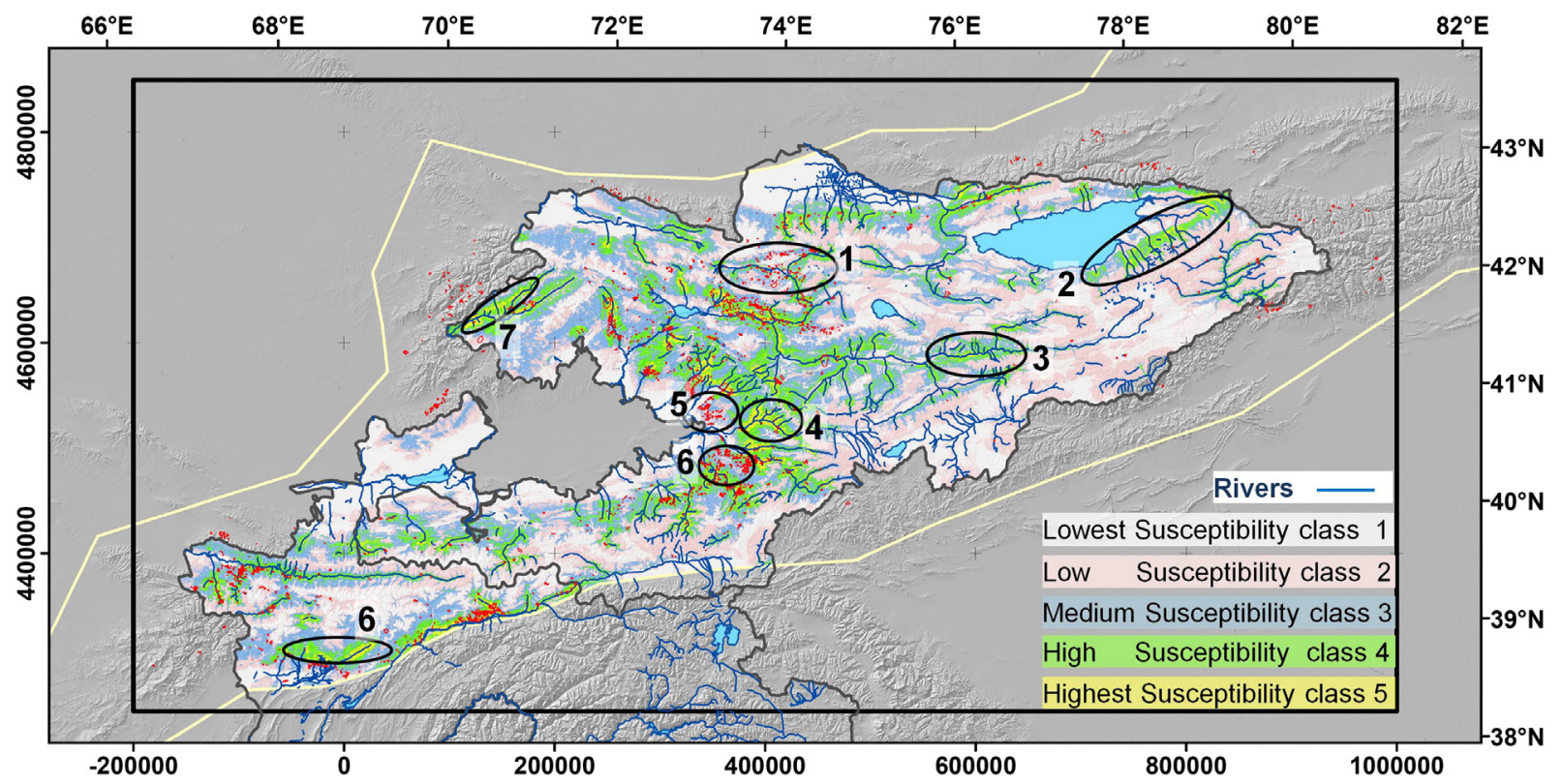

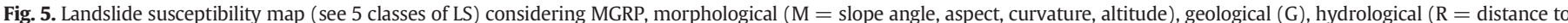

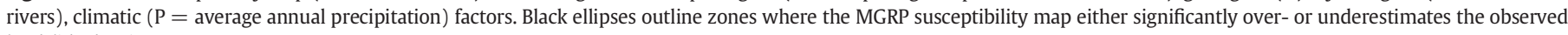
landslide density.

As for the other environmental factor maps, landslide densities computed with respect to the combined distances to faults and $\mathrm{Mw} \geq 6.5$ earthquake epicentres were first attributed to corresponding distance classes. The resulting landslide density map was then multiplied with the MGRP landslide susceptibility map. The resulting 'MGRP + E + F' landslide susceptibility map (MGRP defined above combined with earthquakes 'E' and faults ' $F$ ') is presented in Fig. 7. For this map, the same five susceptibility classes as for the MGRP map were defined: lowest, low, medium, high and highest susceptibility. However, in the MGRP + E + F LS map, the lowest susceptibility class corresponds to multiplied landslide density values of less than 0.05 (0.1 for the MGRP LS map) and highest to values of 15 (10 in the MGRP LS map) mainly in order to obtain classes of a size similar to the one used in the MGRP LS map.

\section{Discussion: performance of susceptibility mapping}

First, we can qualitatively compare the MGR + E + F LS map with the MGRP LS map by calculating the difference between the two maps. To analyse such differences we zoom in on the Central Tien

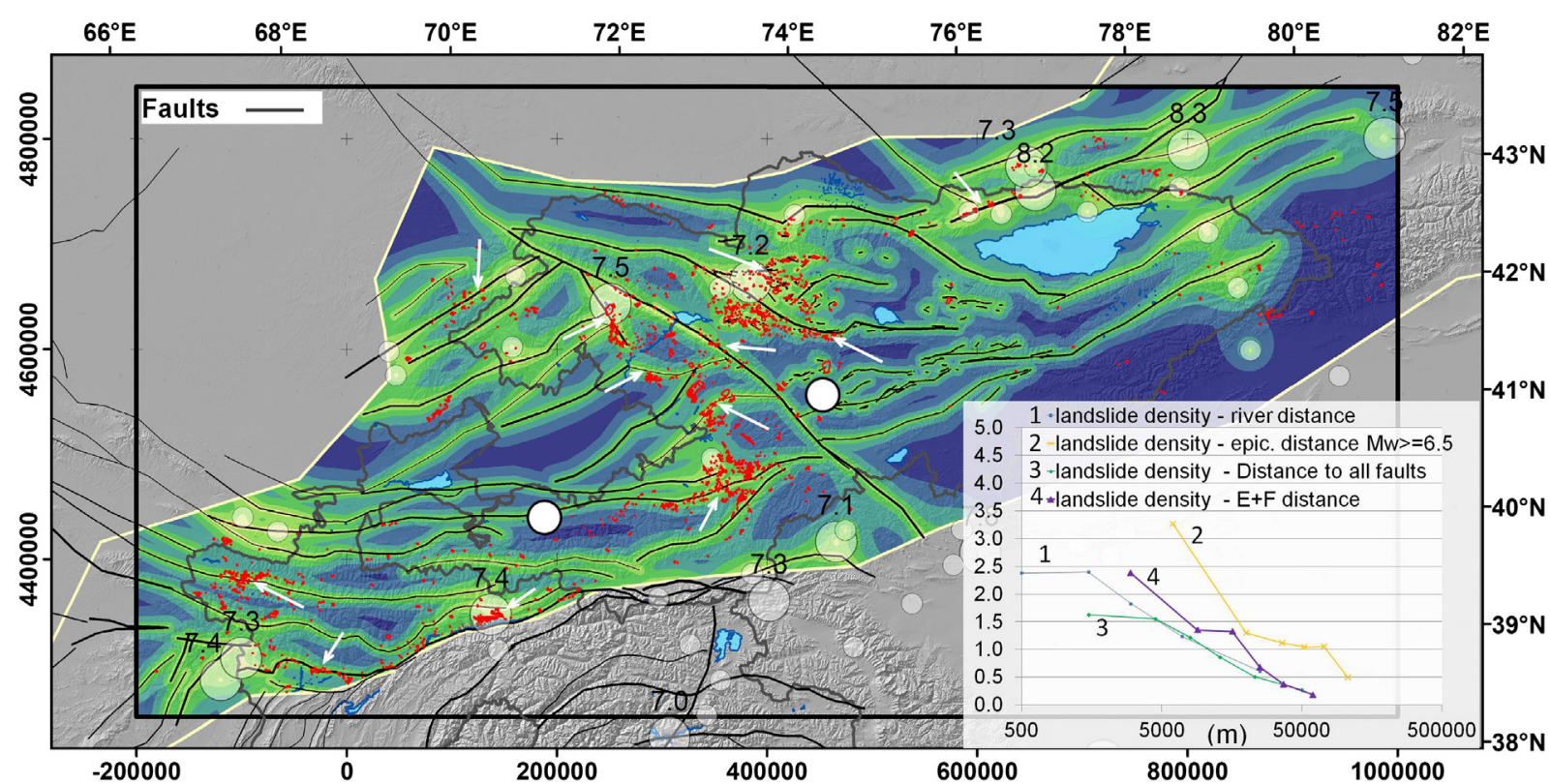

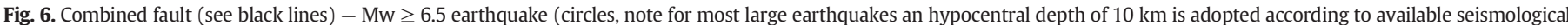

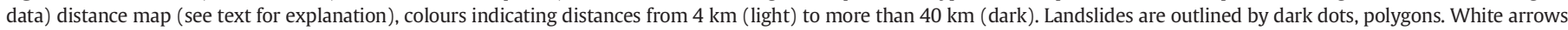


(curve 3), Mw $\geq 6.5$ earthquake epicentres (curve 2), and (curve 4) for the combined distances to earthquakes (E) and faults (F) as shown by the map in this figure. 


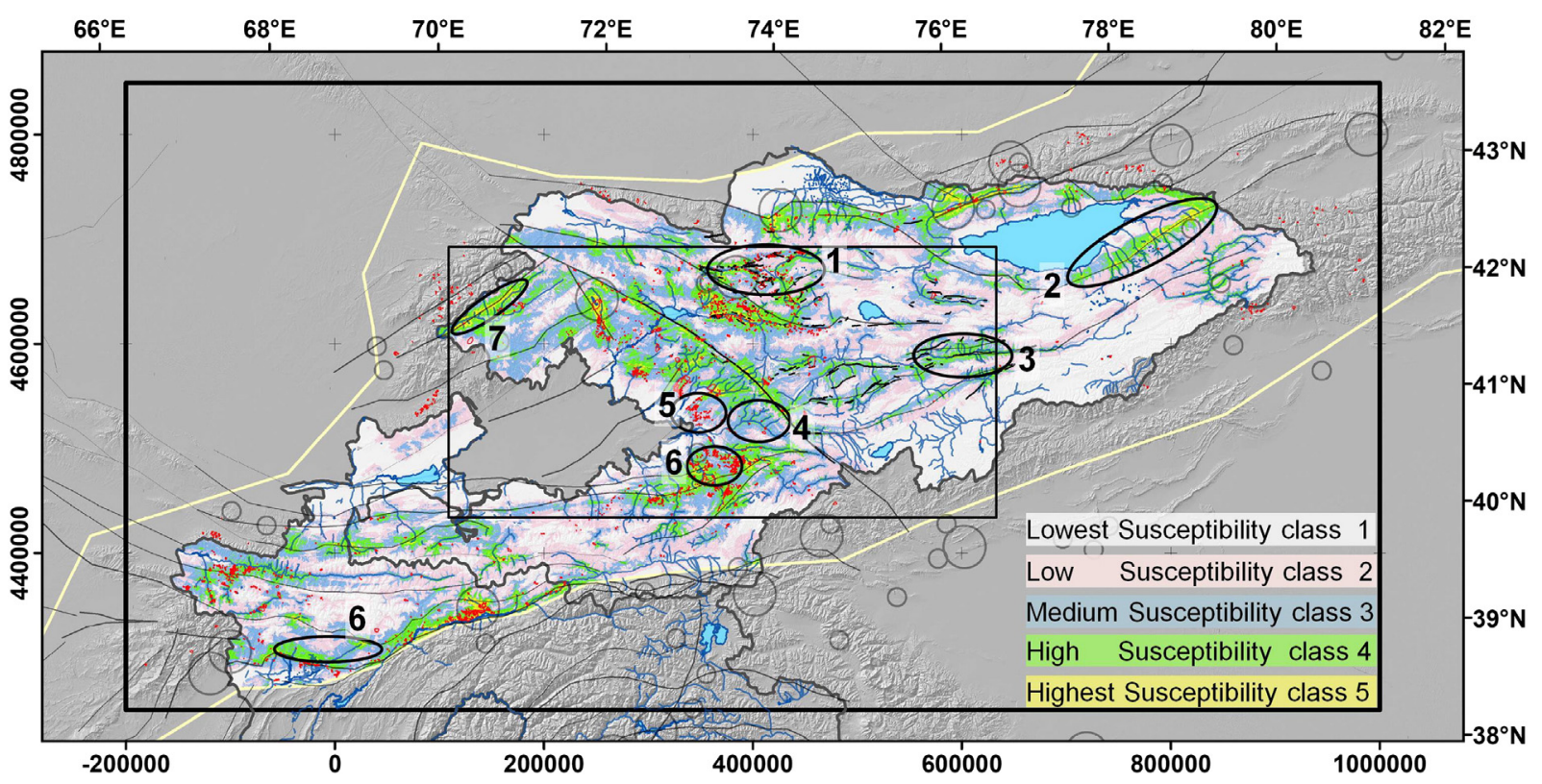

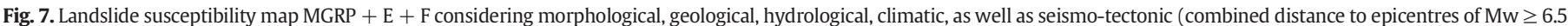

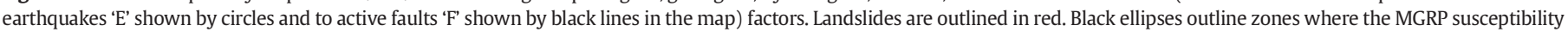

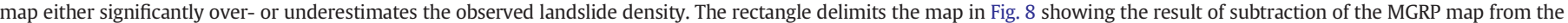
$\mathrm{MGRP}+\mathrm{E}+\mathrm{F}$ map.

Shan and Eastern Fergana region (Fig. 8) where some problematic zones had been outlined on the MGRP LS map (see ellipses in Fig. 5 plotted also on the MGRP + E + F LS map in Fig. 7). Positive differences (MGRP $+\mathrm{E}+\mathrm{F}$ LS $>$ MGRP LS) and negative differences (MGRP $+\mathrm{E}+\mathrm{F}<\mathrm{MGRP})$ are highlighted in the map in Fig. 8, respectively, by violet and by brown areas; zones marked by similar LS values are marked in beige. As could be expected, the MGRP + E + F LS map shows higher landslide susceptibility values along fault zones and near epicentres of past $\mathrm{Mw} \geq 6.5$ earthquakes. Therefore, now much larger LS values were obtained along the faulted border of the Suusamyr Basin (zone 1) and the regions in the south of it, which better reflects the large concentration of landslides in this area (compared to the corresponding MGRP LS map). The same can be observed for zone 6 and partly also for zone 5 near the South-Eastern border of the Fergana Basin. In contrast, in zone 4 the LS values were reduced by adding the seismo-tectonic factors to the susceptibility computations (compared to the previous MGRP LS map). This reduction fits well with the lower landslide concentration in this area - which can therefore be related to the greater distances from past earthquake epicentres and major faults. However, in the two other problematic zones 3 and 7 outlined in the map in Fig. 8, the additional seismo-tectonic component did apparently not improve the fit between landslide susceptibility assessment and known landslide concentration: LS values were increased compared to the MGRP LS map, while only a few landslides were

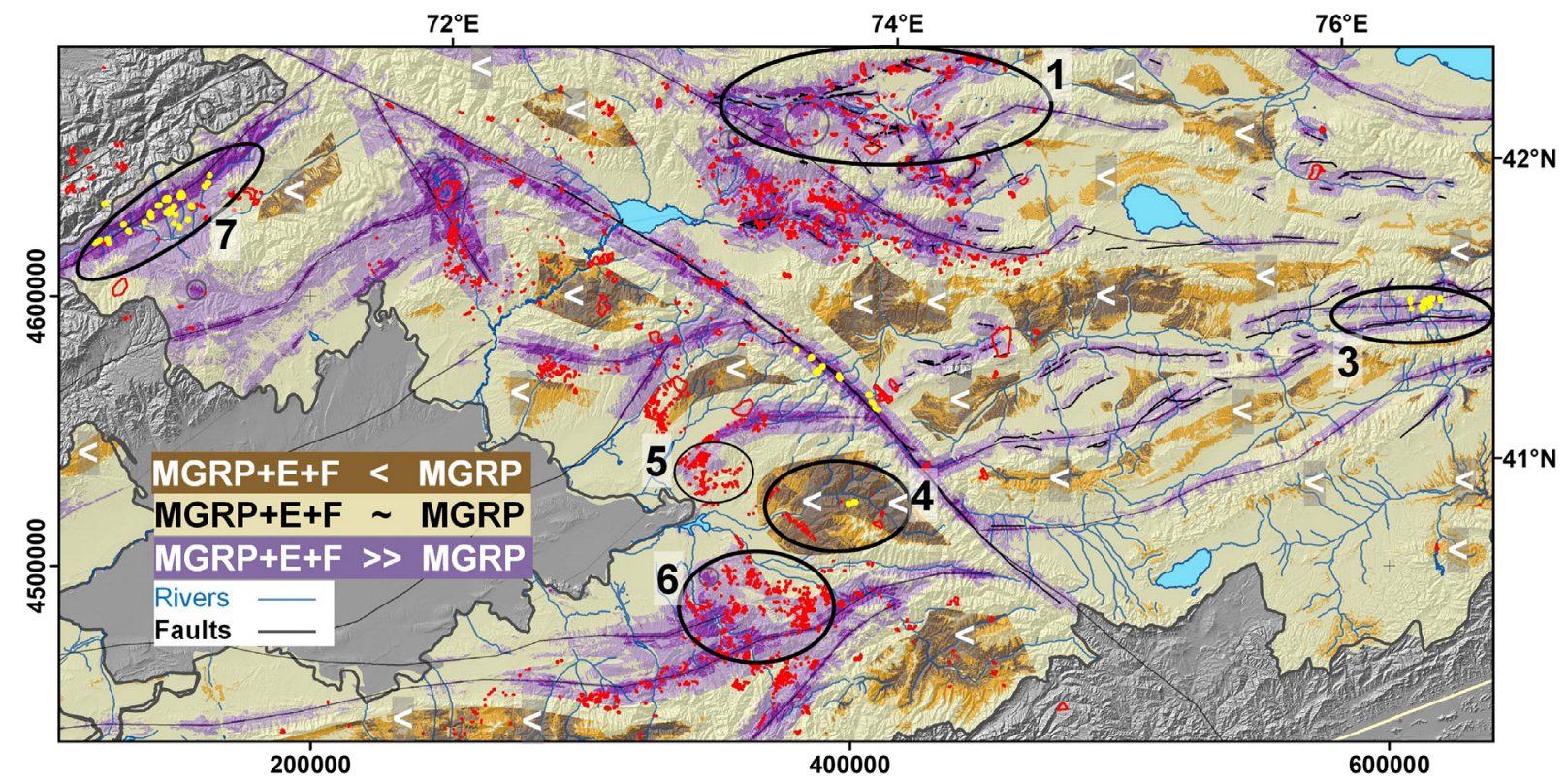

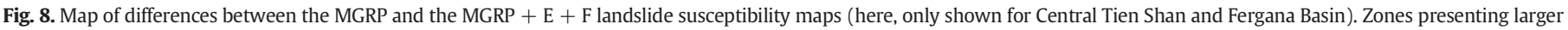

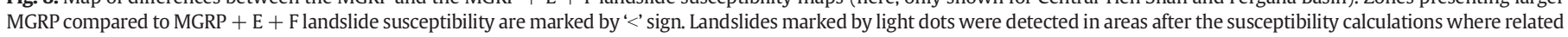
maps either over- or underestimated observed landslide density (based on initially identified landslides shown by dark dots, polygons). 
detected in these zones. Also, along the Talas-Fergana Fault (see location in Fig. 3), crossing obliquely the Tien Shan from SE to NW, the increased LS (reaching maximum values in some areas along the fault) does not well fit the medium concentration of landslides in that area. To explain these discrepancies we first checked if some landslide occurrences might not have been missed in these zones (the check was also performed for zones 2 and 8 not shown in Fig. 8 but marked on Figs. 5 and 7). Landslides detected through this verification are outlined in yellow in Fig. 8. First, we verified the completeness of our landslide inventory in zones 2 and 3. There, we met two problems (already outlined by Havenith et al., this issue): the zones are not entirely covered by high-resolution imagery and many areas are located at higher altitudes where we could not clearly distinguish landslide from moraine material (considering the available image quality). Nevertheless, some additional clear landslides could be detected (see yellow dots in zone 3 ) - but these new detections do not significantly increase the previously observed landslide concentration. Thus, here we consider that both LS maps still overestimate the known landslide activity probably because the rocks are particularly strong in these areas. For zone 4, also a few additional slope failures were detected, but the concentration of landslides is still small compared to the neighbouring zones. Thus, the larger distance of this zone to past earthquakes and major faults might be the cause of the reduced slope instability there. Most additional landslides (about 35 newly mapped landslides) were detected in zone 7 in the western Tien Shan (see concentration of yellow outlines in zone 7 in Fig. 8), where the previous mapping of landslides was obviously incomplete. All the newly detected landslides are located along the NE-SW oriented fault crossing this zone, which fits well with the increased LS represented by the MGRP + E + F map (highest LS class) compared to the slightly lower LS of the MGRP map (high LS class). It should also be noted that additional landslides were detected along the Talas-Fergana fault (see yellow outlines in the middle of the map in Fig. 8). With these additional landslides, we now observe a medium to high landslide concentration almost all along the Talas-Fergana Fault (besides for the SE segment located at altitudes higher than $2500 \mathrm{~m}$ where no landslides had been detected).

If we compare LS shown for zone 8 (north of Dushanbe, Tajikistan) by the MGRP + E + F map with the one indicated by the MGRP map, we can see that it is strongly reduced if the seismo-tectonic factors are considered. Thus, here the larger distance to major faults and past earthquakes could also explain the weaker landslide activity observed in this zone (also after checking, no additional landslides were found in this area).
It should be noted that after the experience of incomplete landslide recording in some zones the whole area was checked again and no additional large slope failures had been found. Thus, now we are quite confident that at lower altitudes $(<2500 \mathrm{~m})$ all rock avalanches and massive rockslides as well as soft sediment slides larger than $5 \cdot 10^{4} \mathrm{~m}^{2}$ have been mapped.

Finally, we assess statistically the quality of the two LS maps (MGRP and MGRP $+\mathrm{E}+\mathrm{F}$ ). The analysis is summarized by the graph in Fig. 9. The columns show both the scarp and landslide densities obtained for the different susceptibility classes both for the MGRP and the MGRP + E + F LS map. From the column graph, it can be seen that the highest susceptibility class of the MGRP $+\mathrm{E}+\mathrm{F}$ map contains five times more landslides than average (about 3 times more for the MGRP map). Thus, we can note that the performance of the MGRP + E + F LS map is clearly higher than the one of the MGRP LS map. The general graph also shows the size of the susceptibility classes (in terms of percentage of the entire map: curve 1 for the MGRP LS map, curve 2 for the MGRP $+\mathrm{E}+\mathrm{F}$ map) and the percentage of landslides contained in it (curve 3 for MGRP map, curve 4 for the MGRP $+\mathrm{E}+\mathrm{F}$ map). If we combine all these graphs, it can be seen that the maximum density of landslides in the highest LS class is due to the small size of the LS class and the relatively large number of landslides. However, the total surface area of landslides is largest for the high LS class (the medium LS class for the MGRP map) because these LS classes are much larger. Therefore, we consider the landslide density in the highest LS class as 'specifically high' and the one of the high LS class as 'generally high'. The landslide density of the other classes is average (around 1 ) for the medium class and low $(0.3<\mathrm{LS}<0.7)$ and lowest $(<0.2)$ for the low and lowest LS class, respectively.

The performance of the maps indicated above cannot directly be considered as prediction potential as we did not divide the landslide inventory into a 'training set' and 'validation set'. Only landslides not considered for the LS mapping (the 'validation set') and for which the fit with computed LS (based on the 'training set') can be tested may be used to assess this prediction potential (Chung and Fabbri, 1999). However, from a LS study performed over such a large extent (almost covering an entire mountain range) we may at least infer that especially the MGRP + E + F LS map reproduces well the trend of the observed landslide activity (besides for zones 2 and 3 where most likely specific lithological or structural aspects were not well taken into account). Further, the landslides detected in zone 7 after completion of the LS computations may be considered as a small 'validation set' for this specific zone that confirms the high LS computed there.

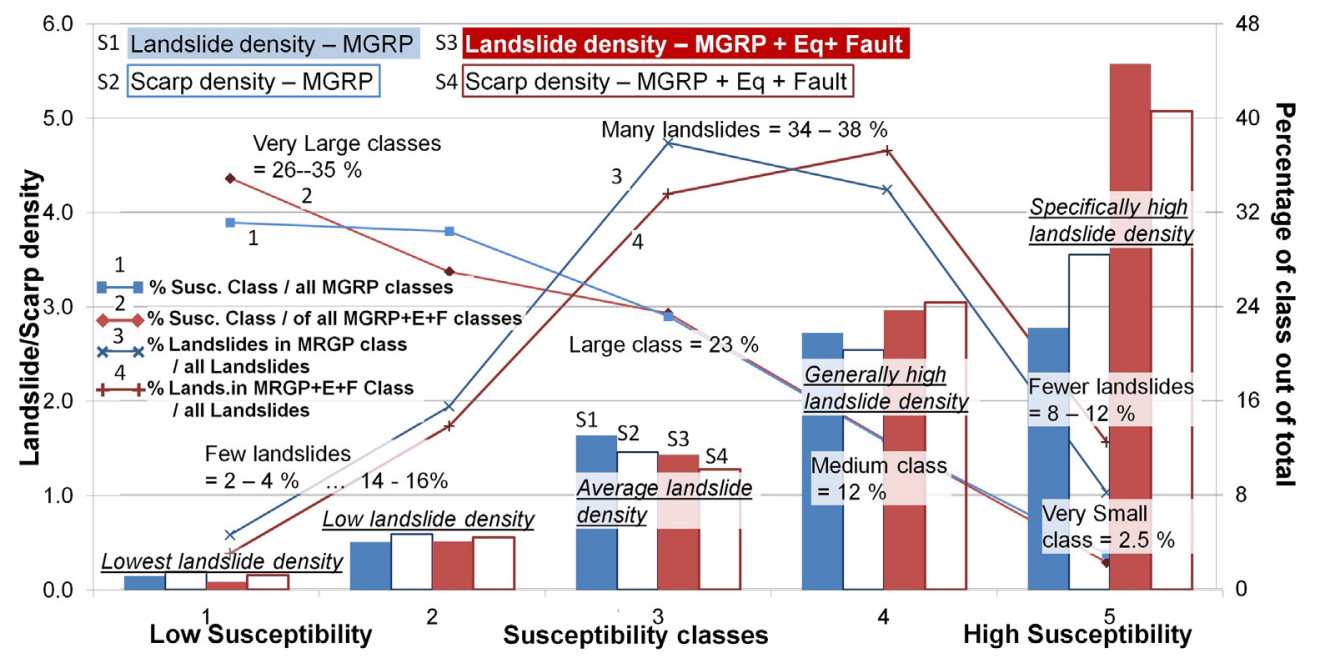

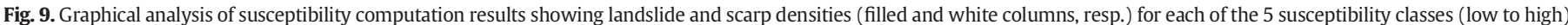

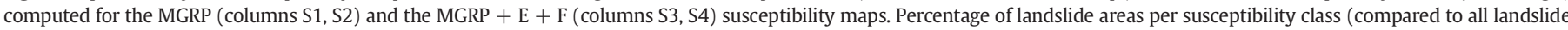

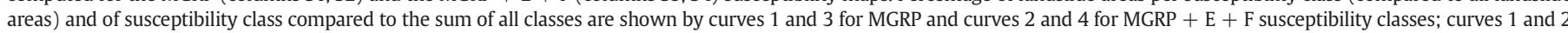
indicating susceptibility class \%; curves 3 and 4 indicating landslide class \%. 


\section{Conclusions}

In this paper we analysed landslide susceptibility for a large part $(1200 * 600 \mathrm{~km})$ of the Tien Shan, Central Asia. This study is based on a new landslide inventory and a recently compiled set of hazardrelevant morphological, geological, climatic-hydrologic and seismotectonic information. Landslide susceptibility was analysed with respect to the aforementioned factors using the Landslide Factor analysis. The correlations between landslide occurrences and the various factors show that the distances to rivers as well as to faults and past earthquakes most strongly constrain the susceptibility of slopes to landslides. For a series of zones, it could be observed that the landslide susceptibility computed by considering the additional seismo-tectonic factors fits better the observed concentration of landslides than those computed for the other factors alone. Here, it should be noted that only the short-distance spatial relationship between landslide location and earthquake epicentres and fault lines (outcrops) was analysed in this paper. There are also a series of examples of remote effects of earthquakes on slope failure activation that were not considered here. The strongest remote effects are known for several deep focal Mw $>6.5$ earthquakes in the Hindu Kush and Pamir that caused extensive activation of monitored landslides in the Angren mining region, Uzbekistan (Niyazov and Nurtaev, 2014), in former mining in Kyrgyzstan (Torgoev et al., 2013) and near the Baipaza Hydropower station in Tajikistan (Havenith et al., 2013), at distances of more than $200 \mathrm{~km}$ up to $700 \mathrm{~km}$ from the hypocentre. One reason for the triggering of various observed geomechanical processes could be related to the particularly low frequency shaking induced earthquakes at those distant sites. However, more detailed investigations and numerical simulations are required to understand these phenomena and to incorporate them into a coupled earthquake-landslide hazard assessment.

Further, within a few areas, the computed landslide susceptibility maps clearly overestimate the observed low sub-regional landslide activity; for two zones in the eastern part of the target region, several reasons may explain the lower landslide density observed there (compared to the one that could be expected according to the landslide susceptibility map): first, these higher mountain (remote) areas are not entirely covered by high-resolution imagery in Google ${ }^{\circledR}$ Earth; thus, smaller mass movements could not be identified; second, increased slope stability there could be caused by particular (yet, at present, unknown) lithological-structural factors - but this can only be confirmed after field visits or by using a more detailed geological map combined with higher resolution remote imagery. For two others in the Central and Western Tien Shan, we show that actually not all landslides had been mapped. After adding these landslides, a higher landslide concentration can be observed that is again best fit by the landslide susceptibility map additionally implementing correlations with the seismo-tectonic factors because most newly detected landslides are located along fault zones. But, why did we mention the problem of undercounting of landslides in those small regions, while we might as well have hidden this aspect? Actually, we wanted to show that landslide susceptibility mapping might help assessing the validity of the existing landslide inventory, especially in remote areas. At present, we are applying a similar stepwise approach to landslide recordingsusceptibility mapping under similar (and even less favourable - due to dense vegetation) conditions along the Western Branch of the East African Rift where the landslide inventory controls the susceptibility mapping and vice versa. The next step is to subdivide the complete inventory into landslide types, distinguishing between source and depositional areas and to produce type-specific susceptibility. Therefore, we would adopt a method similar to the one used by Hermanns et al. (2012). Notwithstanding the good fit between computed landslide susceptibility maps and observed landslide distributions, the limits of landslide susceptibility assessment need to be clearly outlined: the presented maps only give a partial estimate of landslide hazards. They do not provide any indication on the important temporal landslide hazard component (including occurrence in time and recurrence of events) and on possible coupled hazards such a river damming by landslides, dam breaches and related lake outbursts.

\section{Acknowledgements}

Part of this study has been supported by the NATO Science for Peace Project (983289) 'Prevention of landslide dam disasters in the Tien Shan, LADATSHA', 2009-2012. We thank the The State Agency on Geology and Mineral Resources of the Kyrgyz Republic (Zhukov Yu. V.) as well as the Ministries of Emergency Situation of the countries of Kyrgyzstan and Tajikistan for providing inputs for the digital geological map. We are also grateful to the Institute of Water Problems and Hydropower of the National Academy of Science of the Kyrgyz Republic (Kuzmichenok V. A.) for having provided the basic map allowing us to produce the digital average annual precipitation map of Kyrgyzstan.

\section{References}

Abdrakhmatov, K.Ye., Havenith, H.-B., Delvaux, D., Jongmans, D., Trefois, P., 2003. Probabilistic PGA and Arias Intensity maps of Kyrgyzstan (Central Asia). J. Seismol. 7, 203-220.

Aleotti, P., Chowdhury, R., 1999. Landslide hazard assessment: summary review and new perspectives. Bull. Eng. Geol. Environ. 58, 21-44.

Bindi, D., Abdrakhmatov, K.Ye., Parolai, S., Mucciarelli, M., Grunthal, G., Ischuk, A., 2012. Seismic hazard assessment in Central Asia: outcomes from a site approach. Soil Dyn. Earthq. Eng. 37, 84-91.

Braun, A., 2010. Investigation of landslide susceptibility in Maily-Say, Kyrgyzstan, with data mining methods. Master's Thesis, Georesources Management. RWTH Aachen, Germany (131 pp.).

Carrara, A., Cardinali, M., Guzzetti, F., Reichenbach, P., 1995. GIS technology in mapping landslide hazard. In: Carrara, A., Guzzetti, F. (Eds.), Geographical Information Systems in assessing natural hazards. Kluwer Academic Press, Dordrecht, The Netherlands, pp. 135-175.

Chung, C.F., Fabbri, A., 1999. Probabilistic prediction models for landslide hazard mapping. Photogramm. Eng. Remote Sens. 65, 1389-1399.

Clerici, A., Perego, S., Tellini, C., Vescovi, P., 2002. A procedure for landslide susceptibility zonation by the conditional analysis method. Geomorphology 48, 349-364.

Cobbold, P.R., Davy, P., Gapais, D., Rossello, E.A., Sadybakasov, E., Thomas, J.C., Tondji Biyo, J.J., de Urreiztieta, M., 1993. Sedimentary basins and crustal thickening. Sediment. Geol. 86, 77-89.

Durville, J.L., Méneroud, J.P., 1982. Phénomènes géomorphologiques induits par le séisme d'El Asnam, Algérie. Comparaison avec le séisme de Campanie, Italie. Bull. liaison Labo. P. et Ch. 120, 13-23 (in French).

Evans, S., Roberts, N., Ischuk, A., Delaney, K.B., Morozova, G.S., Tutubalina, O., 2009. Landslides triggered by the 1949 Khait Earthquake, Tajikistan, and associated loss of life. Eng. Geol. 109, 195-212.

Gubin, I.E., 1960. Patterns of seismic manifestations of the Tajikistan territory (geology and seismicity). Academy of Sciences of USSR Publishing House, Moscow (464 pp., (in Russian))

Harp, E.L., Wilson, R.C., Wieczorek, G.F., 1981. Landslides from the February 4, 1976, Guatemala Earthquake. USGS, Washington (44 pp.).

Havenith, H.B., Bourdeau, C., 2010. Earthquake-induced hazards in mountain regions: a review of case histories from Central Asia - an inaugural lecture to the society. Geol. Belg. 13, 135-150

Havenith, H.B., Strom, A., Jongmans, D., Abdrakhmatov, K., Delvaux, D., Tréfois, P., 2003. Seismic triggering of landslides, Part A: field evidence from the Northern Tien Shan. Nat. Hazards Earth Syst. Sci. 3, 135-149.

Havenith, H.B., Strom, A., Cacerez, F., Pirard, E., 2006a. Analysis of landslide susceptibility in the Suusamyr region, Tien Shan: statistical and geotechnical approach. Landslides 3, 39-50.

Havenith, H.B., Torgoev, I., Meleshko, A., Alioshin, Y., Torgoev, A., Danneels, G., 2006b. Landslides in the Mailuu-Suu Valley, Kyrgyzstan - hazards and impacts. Landslides 3, 137-147

Havenith, H.B., Abdrakhmatov, K., Torgoev, I., Ischuk, A., Strom, A., Bystrický, E., Cipciar, A. 2013. Earthquakes, landslides, dams and reservoirs in the Tien Shan, Central Asia. In: Margottini, C., Canuti, P., Sassa, K. (Eds.), Landslide Science and Practice. 6. Springer Verlag, Berlin Heidelberg, pp. 27-31.

Havenith, H.-B., Strom, A., Torgoev, I., Torgoev, A., Lamair, L., Ischuk, A., Abdrakhm atov, K., 2015. Tien Shan Geohazards Database: earthquakes and landslides. Geomorphology, Special Issue 'Geohazards Databases' (this issue).

Hermanns, R.L. Hansen, L., Sletten, K., Böhme, M., Bunkholt, H.S.S., Dehls, J.F., Eilertsen, R.S., Fischer, L., L'heureux, J.S., Høgaas, F., Nordahl, B., Oppikofer, T., Rubensdotter, L., Solberg, I.-L., Stalsberg, K., Yugsi Molina, F.X., 2012. Systematic geological mapping for landslide understanding in the Norwegian context. In: Eberhardt, E., Froese, C., Turner, A.K., Leroueil, S. (Eds.), Landslides and engineered slopes: protecting society through improved understanding. Taylor \& Francis Group, London, pp. 265-271.

Ishihara, K., Okusa, S., Oyagi, N., Ischuk, A., 1990. Liquefaction-induced flow slide in the collapsible loess deposit in Soviet Tajik. Soils Found. 30, 73-89. 
Jibson, R.W., Harp, E.L., Michael, J.A., 1998. A method for producing digital probabilistic seismic landslide hazard maps: an example from Los Angeles, California Area. U.S. Geological Survey, Open-file Report, pp. 98-113.

Miles, S.B., Ho, C.L., 1999. Rigorous landslide hazard zonation using Newmark's method and stochastic ground motion simulation. Soil Dyn. Earthq. Eng. 18 305-323.

Nadim, F., Kjekstad, O., Peduzzi, P., Herold, C., Jaedicke, C., 2006. Global landslide and avalanche hotspots. Landslides 3, 159-173.

Niyazov, R., Nurtaev, B., 2014. Landslides of liquefaction caused by single source of impact Pamir-Hindu Kush earthquakes in Central Asia. In: Sassa, K., Canuti, P., Yueping, Y. (Eds.), Landslide Science for a Safer Geoenvironment. 3. Springer Verlag, Cham Heidelberg New York Dordrecht London, pp. 225-232.
Schlögel, R., 2009. Detection of recent landslides in Maily-Say Valley, Kyrgyz Tien Shan, based on field observations and remote sensing data. Master's Thesis, Geological Sciences. University of Liege, Belgium (133 pp.).

Schlögel, R., Torgoev, I., de Marneffe, C., Havenith, H.-B., 2011. Evidence of a changing distribution of landslides in the Kyrgyz Tien Shan, Central Asia. Earth Surf. Process. Landf. 36, 1658-1669.

Torgoev, I., Niyazov, R., Havenith, H.B., 2013. Tien-Shan landslides triggered by earthquakes in Pamir-Hindukush zone. In: Margottini, C., Canuti, P., Sassa, K. (Eds.), Landslide Science and Practice. 5. Springer Verlag, Berlin Heidelberg, pp. 191-197.

Yin, K.L., Yan, T.Z., 1988. Statistical prediction model for slope instability of metamorphosed rocks. Proceedings of 5th International Symposium on landslides, Lausanne Switzerland 2, pp. 1269-1272. 